\title{
A Qualitative Examination of Cross-Cultural Supervision: Toward a Revised Model
}

\author{
${ }^{1}$ Matthew R. Shupp, ${ }^{2}$ R. Scott Mattingly \\ ${ }^{1}$ Shippensburg University of Pennsylvania, USA \\ ${ }^{2}$ DeSales University, USA
}

\begin{abstract}
Little attention has been given to the impact of cross-cultural difference on the supervisory relationship. This qualitative study sought to provide new insights for capitalizing upon these differences. Results indicated varied perceptions regarding the definition of "culture," a relationship between cultural differences and supervision style, and the importance of interpersonal dynamics within supervision. Recommendations are provided in the form of valuable cross-cultural supervision practices and a revised supervisory model.
\end{abstract}

\section{Introduction}

The successful acclimation of new professionals into educational environments, specifically the field of student affairs, is critical for responding appropriately to the challenges of the time. Acclimation is not a given, however, as evidenced by a high attrition rate within the first five years of employment as full-time professionals in the field [4], [8], [34], [42]. Often, the reality of full-time positions does not match graduate student experiences [8], [22], [39]. Marsh [27] noted that new professionals often need assistance with evaluating short-term job and education decisions, long-term career goals, and establishing work-life balance. Supervision for these emerging professionals is, therefore, critical.

The Harper Dictionary of Contemporary Usage indicates the etymology of supervise dates back to 1588 when it meant to look over. It is from Medieval Latin (c.700 - c.1500) supervisus, the Past Participle of supervidere meaning to "oversee or inspect," from Classical Latin super "over" + videre "see". The literal definition of "to oversee and superintend the work or performance of others" is attested from c.1645; supervisor in this sense of "one who inspects and directs the work of others" was first recorded in 1454 [28].

The word supervision is complex, with different interpretations depending upon the circumstances in which it is employed. Although definitions for supervision abound, most settle on a process of overseeing someone to accomplish a task. For the purpose of this manuscript the following definition from Shupp [38] was used: "Supervision is an ongoing process providing guidance and direction while overseeing the performance or operation of a person or group with the intended outcome of both employee and institutional accomplishment". We espouse that supervision is intentional, not sporadic. Although individual supervisors could conduct supervision any number of ways depending on the type of institution and demands of specific offices, effective supervision typically occurs on a consistent basis and has intended outcomes including individual goal setting, institutional goal accomplishment, collaboration, joint-communication, and increased employee competence.

One complication in the student affairs supervision dyad is cultural differences. As Manathunga [26] commented, "[i]n working across different cultures, extra layers of complexity and intellectual challenge are added". This complexity is evident when one reflects upon commonly used definitions of culture. For example, Estrada, Wiggins Frame, and Braun-Williams [17], referencing an earlier definition by Stone, contended that culture "typically has referred to the 'patterned regularities' of certain groups including customs, languages, traditions, beliefs and values". This characterization highlights the deep-seated nature of culture as opposed to something acquired easily over a short span of time. Estrada et al. also noted that "'[c]ulture' is a broader term that may embrace 'race' and other factors that describe a person's self-identity and experiences". This suggests that cultural patterns, while they may be associated with group identity, are interpreted through a unique lens by each individual.

A lack of appreciation for the highly personal nature of culture can lead to emotional misunderstandings and disagreements. For example, many authors have discussed the challenges of stereotyping in cross-cultural supervisory relationships [3], [36], [46]. Manathunga [26] found that this danger was present even for a supervisor and supervisee from the same ethnic background. In such circumstances, shared group identity might lead one party to make 
inaccurate assumptions that fail to account for the other party's unique experiences and self-identity. Many supervisors are ill-prepared for these challenges [14], [39], [44].

Given the complexity of cross-cultural supervisory relationships and the need for more effective preparation among supervisors of new professionals, we sought to answer two questions: How do new professionals define and understand supervision in a cross-cultural context? How are cultural differences related to the supervisory challenges and opportunities identified by new professionals? Using the findings as a springboard, we sought to provide student affairs practitioners with ways of integrating Winston and Creamer's [44] Synergistic Supervision Model into daily supervisory practice in a manner that capitalizes upon cross-cultural relationships.

\section{Literature Review}

Several authors have noted that literature on higher education supervision, particularly crosscultural supervision, is lacking [4], [23], [26], [30], [40], [43]. Supervision has been addressed in research literature from the counseling field dating back to the 1960s [40]. However, even in that field, many authors have asserted a need for more research addressing cross-cultural supervision and leading to corresponding models [1], [13], [17], [25], [41], [46]. Much of the existing scholarship on supervision, particularly cross-cultural supervision in higher education literature, is observational in nature, with fewer empirical studies. Below, using seminal writings from the field of counseling and more recent postsecondary studies, we have highlighted valuable components of supervision and provided an overview of two concepts central to this study, synergistic supervision and multicultural competence.

\subsection{Components of Supervision}

Literature from counseling and higher education has indicated that the power imbalance inherent in supervisory dyads represents a potential source of conflict, leading both parties to feel at risk, particularly when cultural differences are present [1], [6], [12], [13], [17], [26], [29], [37]. Various authors have remarked upon the value of collaboration between supervisors and supervisees, noting that it requires mutual respect and understanding [1], [21], [36], [37], [39], [40], [44]. Before supervisors can respect supervisees' cultures, they must have a firm grasp of their own cultural identity, including biases [5], [17], [25], [26], [29]. They should recognize the complexity of culture rather than focusing on simplistic stereotypes [3], [25], [26], initiate open discussions about culture [3], [6], [11], [12], [13], [17], [18],
[20], [25], [29], [40], [41], and share past and present shortcomings, presenting their mistakes and fears as learning experiences [1], [17], [20], [27], [29], [37], [40]. Drewes [15] summarized the work of several prior studies, saying:

In addition to offering guidance and explicit discussion of culture-specific issues, the supervisor's willingness to be vulnerable and share his or her own struggles, along with providing an opportunity for multicultural activities, helps facilitate a culturally responsive supervisory relationship. (p. 82) Though speaking of counselors, Drewes' recommendations are no less valuable for student affairs practitioners.

Support is a critical aspect of supervision, helping employees to perform their jobs and grow. It includes accessibility, guided reflection on differences and challenges, performance evaluations and ongoing feedback, and guidance on personal circumstances to the extent that they impact work [1], [8], [14], [21], [27], [35], [36], [39], [40], [44], [46]. Support is particularly valuable in cross-cultural relationships, including early attention to establishing feedback mechanisms, resolving cultural conflicts, and discussing misunderstandings [13].

Effective supervisors are careful to set the tone for new supervisees by providing clear expectations [37], [39], [40], [44], [45]. Supervisors should aid new professionals in adjusting to the environment, including navigating campus culture, appreciating institutional values, and understanding the relationship of the department to the institution as a whole [2], [8], [14], [21], [27], [37], [39], [40], [42] . Stock-Ward and Javorek [40] asserted that tonesetting should include "addressing multicultural issues...early on, in a matter-of-fact way". Supervisors can also assist new professionals with "bridg[ing] the gap between graduate education and fulltime employment" [39].

Many authors have commented on the need for professional development to assist supervisors and supervisees in the counseling profession with improving discussions about culture [1], [11], [18], [29], [41]. In student affairs, professional development may include improved graduate curricula, professional associations, mentoring, and staff development efforts [2], [4], [23], [39], [46], and "[e]xposure to models of supervision, as well as active supervision of supervisory activities" [40]. In other words, good supervision begets good supervision.

\section{Conceptual Framework}

\subsection{Synergistic Supervision}

Winston and Creamer's [44] Synergistic Supervision Model is grounded in a cooperative effort between the supervisor and supervisee with a 
focus on joint-effort, two-way communication, and competence and goals. Synergistic Supervision espouses a relationship based upon mutual respect. While traditional supervision models often utilize a top-down approach, Synergistic Supervision levels the proverbial playing field, reducing barriers while increasing communication, building trust, and prioritizing the supervisor/supervisee relationship. Through this authentic relationship, greater attention is paid to both individual and organizational goals, leading to the betterment of each. The Synergistic Supervision Model contributes to an intentional, participatory, and distributed style of leadership. Tull [42] found that synergistic supervision contributed to new student affairs employees' satisfaction, retention, and advancement. Building on Tull's research, Shupp and Arminio [39] found that synergistic supervision "results in success for both individuals involved as well as the organization".

\subsection{Multicultural Competence}

Pope, Reynolds, and Mueller [32] defined multicultural competence as the "awareness, knowledge, and skills needed to work with others who are culturally different from self in meaningful, relevant, and productive ways". They asserted that multicultural transformation is not merely the purview of campus experts with responsibility for diversity initiatives, but requires systematic attention to diversity and multicultural competence. This conceptualization was predicated on the authors' expansive definition of multicultural, which celebrates "all of [the] social identities...[that] shape who we are and how we view the world" [33]. Competence is not merely something that we achieve in relation to those who differ from ourselves, but also involves an "understanding of within-group differences" [33].

It is clear that new practitioners need accessible and collaborative supervisors with a multi-faceted skill set. The complexity of these relationships is magnified when cultural differences are present. These differences require not only an internalized multicultural competence, but external modeling of awareness, knowledge, and skills to promote individual growth and institutional achievement.

\section{Methodology}

Through a qualitative constructivist approach, this study sought to provide new insights about cross-cultural supervisory relationships. Valuable cross-cultural supervision practices using Winston and Creamer's [44] Synergistic Supervision Model contributed to the development of a revised model for supervisors to improve their supervision of entry-level professionals. Both positive and negative cross-cultural supervision experiences described by research participants were used to enhance this model.

Narrative inquiry, an approach to qualitative research that presents "ordinary people's oral narratives of everyday experience," grounded our methodology [7]. Clandinin and Connelly [9] remind us of the importance of "turning inward" as we "[watch] outward" when participants construct meaning from their life experience, and we, in turn, interpret their meaning-making. Semi-structured questions guided our interviews, prompting respondents to compare positive and negative supervisory experiences. For example, we asked: What was your graduate school experience with supervision? In what capacity did this supervision occur? How often did this supervision occur? Following this sequence, we inquired: How is your current experience with supervision as a young professional? We also inquired about the impact of supervision and culture on participants' professional growth and about their ideas for strengthening these relationships.

\subsection{Participants}

Participant interviews were the preferred method of revealing human experience in this study. Therefore, interactions between the participants' experiences and those of the researcher were paramount [16], [24]. To fully understand the lived experience of participants in cross-cultural supervisory relationships, purposeful criterion sampling was used to gain information and insight within a particular, homogenous sample [31]. Participation criteria included graduation from student affairs or higher education graduate program, current employment in higher education, and self-identifying as culturally different from their supervisor.

A Call for Participation was sent out via professional listservs and eight individuals expressed interest. A closer investigation of those interested resulted in the elimination of two individuals for their inability to meet specified criteria. A cohort of six participants was selected for the study, but one participant voluntarily removed herself upon realizing that she did not meet the minimum criteria. As a result, we ended with a cohort of five participants, three females and two males with ages ranging from 27 to 30 yearsold, a sample size that has been found suitable for qualitative studies with similar methodologies [9]. Additional demographic information is contained in Table 1. Pseudonyms were used to ensure confidentiality. While face-to-face interviews were preferred, due to geographic constraints, two interviews were conducted via Skype. Each interview lasted no longer than 60 minutes and was transcribed verbatim. Permission to record each interview was obtained in advance. All participants 
signed a consent form disclosing the study's purpose and assuring them of confidentiality.

Table 1. Demographic characteristics of qualitative research participants

\begin{tabular}{|c|c|c|c|c|c|}
\hline Name & Race & Gender & $\begin{array}{l}\text { Institutional } \\
\text { Position }\end{array}$ & $\begin{array}{c}\text { "Institution } \\
\text { Type }\end{array}$ & $\begin{array}{c}{ }^{*} \text { Cultural } \\
\text { Difference } \\
\text { with } \\
\text { Supervisor }\end{array}$ \\
\hline Jenny & White & Female & $\begin{array}{l}\text { Acadenic } \\
\text { Advisor }\end{array}$ & $\begin{array}{l}\text { Large, State- } \\
\text { related }\end{array}$ & $\begin{array}{l}\text { Military } \\
\text { Experience, } \\
\text { Fthnicity, } \\
\text { Gender }\end{array}$ \\
\hline Kate & White & Female & $\begin{array}{l}\text { Assistant } \\
\text { Director, } \\
\text { Student Union }\end{array}$ & $\begin{array}{l}\text { Mid-sized, } \\
\text { Public, State- } \\
\text { related }\end{array}$ & $\begin{array}{l}\text { Experience. } \\
\text { Ethnicity, } \\
\text { Gender }\end{array}$ \\
\hline Mike & White & Male & $\begin{array}{l}\text { Career } \\
\text { Counselor }\end{array}$ & $\begin{array}{l}\text { Private, } \\
\text { Liberal Arts }\end{array}$ & $\begin{array}{l}\text { Worldview } \\
\text { (Diversity of } \\
\text { Work } \\
\text { Experience), } \\
\text { Location } \\
\text { (Urban vs. } \\
\text { Rural), Gender }\end{array}$ \\
\hline Jack & Indian & Male & $\begin{array}{l}\text { Assistant } \\
\text { Director, } \\
\text { Housing }\end{array}$ & $\begin{array}{l}\text { Mid-sized, } \\
\text { Public, State- } \\
\text { related }\end{array}$ & $\begin{array}{l}\text { Experience. } \\
\text { Ethnicity, Race }\end{array}$ \\
\hline Janice & White & Female & $\begin{array}{l}\text { Admissions } \\
\text { Counselor }\end{array}$ & $\begin{array}{l}\text { Mid-sized, } \\
\text { Public, State }\end{array}$ & Race, Gender \\
\hline
\end{tabular}

\subsection{Analysis of Narratives}

Jones, Torres, and Arminio [24] characterized member checking as a primary means of determining research worthiness. Member checking occurred on two separate occasions. The first sought feedback on interview transcriptions. As like-themes emerged, portions of the researchers' interpretations were provided to the participants to validate the authenticity of the work. Initially, data was sorted individually via primary coding by the researchers. Then, each researcher developed categories of like-themes. We then compared and contrasted each theme via axial coding to settle on emergent narrative stories from each participant. In the next section, we explicate and verify the identified themes through participants' quotes.

\section{Findings}

Although the researchers initially asked about cultural differences between supervisees and their supervisors in the participant selection phase, the researchers avoided asking them to define their cultural differences directly during the data collection phase, allowing the topic to arise organically before encouraging deeper reflection. In this way, the researchers could ensure that the authenticity of participants' responses was not compromised. Results from the study generated three distinct themes: varying perceptions of cultural difference, a relationship between cultural differences and supervision style, and the importance of interpersonal relationships.

\subsection{Varying Perceptions of Cultural Difference}

Similar to the multi-faceted definitions of culture highlighted in the literature, the five participants described many types of difference in relationship to their supervisors. Some described differences commonly associated with cultural diversity. Janice, a White female serving as an admissions counselor, mentioned gender and race; Kate, a White female working in a student union, mentioned gender, race, and sexual orientation; while Jack, an Indian male employed in student housing, discussed ethnicity. Specifically, Jack spoke about frequently being the only individual of Indian heritage in any given situation. He appeared to have wrestled with his cultural identity more than other participants, saying "[w]hen there are other representatives of my ethnicity in the room I'm actually uncomfortable," a feeling attributable to constant reminders of difference that made him "want to run away from those differences". He expressed mixed feelings about being asked by his supervisor to conduct a program on Indian culture, noting that:

It's a mixed bag because you're... always being asked to do things like that; but on the other hand, it was always gentle in how it was said... [and efforts] to make diversity a priority in our decisionmaking really had a great effect on me.

While the participants described varying understandings of cultural difference, each case demonstrated the impact of these nuances on their supervisory relationship.

Differences were also expressed in experiential terms. Jenny, a White female in academic advising, commented on challenges stemming from her lack of military experience as compared to her supervisor and other colleagues. She described the environment as "a completely different world" with individuals having "completely different mindsets about everything". Whereas Jack felt challenged by constant reminders of his minority status throughout his life, Jenny struggled with being a minority for the first time, speaking metaphorically:

It's...like, most of the time, not being a part of an inside joke,...not that it hurts my feelings or anything. It's just I've never been the minority in any situation and, with my supervisor also being in on the joke, it's just so different. Jenny also spoke of literal jokes, saying:

I wonder, is this inappropriate a lot of the time? I know we're all joking and we all make jokes about..."Oh, look who's in the military, all the minorities, and the two white people on the team aren't in the military". But, I think there's a line that we all cross sometimes. 
These conversations occurred "on a daily basis," making the office culture difficult for Jenny to navigate.

Both Janice and Mike, a White male career counselor, described two recent supervisors with opposite backgrounds. Janice spoke directly to racial differences among her supervisors:

One of my supervisors is a Black male and the other [is a] White male. [Yet, I feel] very supported. I've...been able to [ascertain] different views, especially from a Black male perspective because we work with a lot of students that identify as Black or African American and so he can talk more [directly to] their experiences. [He taught me] that we need to look more at each student for what we can give to them and what they can give to us. With the White male, there hasn't been as much time or direct contact.

Mike's first supervisor "was a female who had a variety of different experiences working all over the country". The second was also a female, but came from a rural background and worked at the same small institution for many years.

Cultural differences often manifested as worldview differences. Jenny attributed communication challenges with her supervisor to military culture. Specifically, she described him as "very straightforward," often telling her what to do or not do, and lacking a "social helping personality, where they want to talk things out". She valued a personal relationship with her supervisor, though he seemed to focus solely on tasks. "He really only meets with [me] if there's a problem," she observed. Mike found his first supervisor's broad experience and collaborative approach eyeopening. He enjoyed the "hands-off" freedom that he was given, stemming from mutual trust. He struggled with the next supervisor, however, whose work history and background were neither broad nor diverse. These differences, in his mind, contributed directly to her micromanagement and discomfort in social situations.

As these examples illustrate, participants' descriptions of difference often blurred the lines between cultural differences, personality differences, work-style preferences, communication styles, etc. This suggest the difficulty of attempting to consider either supervision or culture in isolation. Instead, these various types of difference are so interrelated as to be, at times, indistinguishable, suggesting that supervisors need to merge their efforts in a more comprehensive manner. This revelation is consistent with the deep-seated nature of culture, as defined above in the introduction.

\subsection{Relating Cultural Differences and Supervision Styles}

Study participants frequently related cultural differences to supervisory practices. For several participants, framing experiences in cultural terms seemed to facilitate new insights. Jenny felt stifled by her supervisor's tendency to dictate responsibilities and criticize rather than offering help. She associated this tendency with military culture, a connection supported by relationships with other colleagues who also had military experience. This led to the realization that she needed validation from supervisors, not only for the emotional benefit of mattering but also as a practical means of confirming skills acquired: "I need that pat on the back. I need to be told... when I've done something good so that I continue to do those things". Janice spoke of gender differences and their impact on her experience:

I tend to find that I'm more high-strung or uptight.... I've found with the male supervisors, they've been easier going, which is a good quality; but then, there've been times where I would like to plan something out in more detail and they...push it aside until the day before. I associate it with male/female just because that's been my interaction. Though she filtered her experience through the lens of gender differences, Janice's challenges appeared to stem from contrasting work styles. She acknowledged that her experience was limited, but related difference to negative supervisory behaviours nonetheless. Jack had contrasting reactions to cultural jokes in different contexts. He described an off-putting interaction with the college president, saying:

He stopped and asked if I was going to shave my beard. And it was one of those moments literally right before I was about to introduce him...I just remember it being a very awkward experience for me. I took offense to it, not so much that I needed to report it to HR; but, more so that I'm busting my butt for you and I don't feel appreciated in this moment.

On the other hand, when his supervisor made a joke, Jack was more accepting:

We were going through some applications together and he's like, "Oh, that sounds like an Indian name" and then he says, "Oh we already have one" just in a joking context and I know that to be a "Okay, he's just messing with me;" but, I know him well enough to know that he is somebody that has earned that ability. Just as Mike's positive and negative supervisory experiences hinged on trust, Jack also attributed the differences that he experienced to trust:

Culture is always on my mind; but, I think one of the things my supervisors have done is that they've built a relationship and, as it got stronger and they wanted to talk about those things, there 
was a foundation of trust. I think that's what it all goes back to. The young professional explained that his views of supervision, particularly with regard to cultural differences, were shaped in critical ways by experiences with "more seasoned individuals". Reflecting on negative experiences, he described a cautionary list that he maintained, which included "things that I don't ever want to do because I've seen other people do them". Speaking about positive experiences, he asserted that " $[\mathrm{t}] \mathrm{he}$ most important thing that I learned, the best way to be a good supervisor, is to experience good supervision".

In varied ways, each of our participants connected cultural differences to supervisory styles. In particular, it was apparent that interpersonal relationships between participants and their supervisors greatly influenced how they felt about cultural differences, a theme discussed in greater depth below.

\subsection{Importance of Interpersonal Relationships}

Considering our participants' stories, it seems clear that the existence of a trusting relationship was critical for enabling supervisors and supervisees to approach cultural differences in a comfortable way that affirmed the value of diversity. This latter point was particularly true for Jack. His current supervisor encouraged him to share his experiences as a minority with students and shaped Jack's appreciation for the value of diversity by demonstrating multicultural competence. As Jack explained:

I truly believe that having someone supervise you from a different culture can have a very significant effect. ...There is a phenomenal opportunity for majority voices to be supervised by individuals from the minority because I think it may allow them to listen to a voice they may not have heard before or they've never heard with that kind of authority. ...I see it as a great opportunity and one of the strengths of our field. I worry that diversity may be getting lost. We know there is a high burnout rate and I would love to look at that burnout rate and how it relates to the diversity within our field 'cause my hunch is that some of those people that burn out might be from diverse backgrounds because they feel that their voice is lost. These words demonstrate multicultural competence in the form of knowledge, awareness, and a desire for new knowledge and skills Although her supervisor differs from her by race and sexual orientation as well, Kate observed gender as the most powerful difference, articulating that:

Gender plays a role because, at points...we get in trouble. ...He treats the males different than the females.... He'll let the males get away with certain things whereas us, we could get our heads chopped off. In contrast, a more positive experience with a prior male supervisor suggests that interpersonal relationships may have had a greater impact than gender differences. Speaking of the previous supervisor, Kate noted that:

He was my supervisor; but, we were also very close. So, I could...talk about work-related stuff and he would give me great advice to work through a problem, to come to a conclusion; but, he would also be there to help me and talk about family issues or class. I don't think gender played a role. By using an aggressive interpersonal approach, Kate's current supervisor may have curbed growth in multicultural competence, limiting her ability to learn from difference. Contrasting communication and work styles also amplified the experiential and worldview differences that existed between Mike and a former supervisor. Mike possessed varied experiences across different types of institutions for short periods of time and his supervisor possessed in-depth experience at a single institution. As discussed above, his relationship with this supervisor was strained by perceived distrust and micromanagement. If a more positive interpersonal relationship had existed, the two may have benefited from one another's diverse perspectives.

In summary, the themes from the study indicated varied perceptions regarding the definition of "culture," a relationship between cultural difference and supervision style, and the importance of interpersonal relationships for supervision. These themes provide a foundation for continued discussion. Below, we provide a cautionary note regarding limitations of our study and suggest ideas for future research, relate our findings to existing literature on successful practices in supervision, use the findings as a springboard for practitioner recommendations, and close with a proposed model of supervision.

\section{Limitations and Recommendations for Future Research}

While the results of this study illuminated the importance of cross-cultural considerations for supervisory relationships, it is not without its limitations. Qualitative methods were intentionally employed in order to capture the unique experiences of the participants. Yet, as is common in this method of research, the low participant number $(\mathrm{N}=5)$ and knowledge gained might not generalize to other people or settings. Likewise, the credibility of qualitative research is often scrutinized due to the researcher's subjective review of the data and the potential for the results to be influenced by biases. Constant refinement of trustworthy research practice must be employed given the idiosyncrasies of qualitative research. As with the participants in Shupp and Arminio's [39] 
precursory study, in spite of efforts to attract diverse participants, our calls elicited a high percentage who identified as White and female. Future research that seeks greater diversity in participants and employs mixed-methods approaches may add additional breadth to the investigation and, thus, elicit refined outcomes. Still, we believe that the following recommendations are supported by the findings.

\section{Recommendations for Practice}

The results of this study appear to support existing literature on valuable cross-cultural practices in supervision. Below, we elucidate and expand upon successful supervisory practices established in the literature and, most notably, we provide a conceptual definition of cross-cultural supervision and propose a revised model of supervision to guide practitioners within a crosscultural context.

\subsection{Support for Existing Literature}

The results mirror prior research, supporting the benefits of a helping supervisory relationship for aiding new practitioners in adjusting to their professional environment. A supervisor who views supervision as collaborative provides clear expectations and support for the objectives of the supervisee's position, professional development, and work-life balance. Recall the negative impact upon Jenny when her supervisor only spoke to her to criticize rather than offering her ongoing support to facilitate professional growth.

To facilitate supervisees' comfort with cultural discussions, supervisors must address culture explicitly while modeling awareness and openness. This approach requires that supervisors understand their own cultural identity, including biases, and recognize each supervisee's uniquely constructed identity. It also requires that they facilitate supervisees' productive cross-cultural relationships with students and colleagues. Recall Jack's uncomfortable interaction with the college president, who inquired about whether or not Jack would shave his beard. Jack's cultural identity compelled him to have a beard and the president's comment was either ignorant of this fact, insensitive to it, or both. Contrast this with Jack's supervisor, who discussed cultural identity and assisted Jack with facilitating students' multicultural competence, contributing to Jack's growth.

\subsection{Redefining Supervision in Light of Culture}

As illuminated in the findings, perceptions of cultural difference in the context of supervision differed greatly among participants. The relationship between cultural identity and supervision was intricate, with participants describing the two concepts in an interrelated manner reflective of the complexity and deepseated nature of culture. As a result, we believe it is useful to create a revised definition of supervision for student affairs, one which gives due consideration to culture.

To achieve a more nuanced definition, we filtered Shupp and Arminio's [39] operational definition of synergistic supervision through the lens of multicultural competence: Cross-cultural supervision is an ongoing process that provides guidance and direction while overseeing the performance or operation of a person or group with the intended outcome of both employee and institutional accomplishment, and that gives attention to the relationship between a supervisor's individual cultural patterns and a supervisee's individual cultural patterns, including group identity, self-identity, worldview, and the experiences that have shaped both identity and worldview.

\subsection{Toward a Revised Model of Supervision}

The complex relationship between culture and supervision also leads to practical questions about the most effective methods for supervising new professionals. A revised definition is useful for prompting supervisors to be more mindful of the role of culture, but does not in itself lead to actionoriented steps. In the same way that existing definitions of supervision can be enhanced by consideration of culture, we believe that culture can be incorporated into existing models of student affairs supervision for greater contributions to daily practice. This is further supported by the third emergent theme from our study, the importance of interpersonal relationships for maximizing crosscultural supervisory experiences. To achieve greater clarity and practicality, we propose a crosscultural model of supervision, developed using the themes from our findings as a basis for identifying commonalities between Winston and Creamer's [44] Synergistic Supervision Model, Pope et al.'s [33] description of multicultural competence, and Drewes' [15] proposal for integrating culture and supervision in counseling. Specifically, we noted three appropriate points of intersection among these frameworks.

First, with the cooperative process from synergistic supervision, including an authentic relationship forged between supervisor and supervisee, we incorporated the supervisor's awareness, openness, and attention to cultural factors, including sharing personal struggles around culture, as discussed by Drewes [15]. 
Second, we linked collaborative efforts and two-way communication from synergistic supervision to the need for "guidance about and explicit discussion of culture-specific issues" [15]. Third, we integrated a focus on competence and goals with the need to provide "an opportunity for multicultural activities". When approached in this integrated way, the relationship represents an opportunity to enhance the multicultural competence of both parties. In particular, as Figure
1 demonstrates, the helping process, including openness, vulnerability, etc., promotes awareness; collaborative efforts and two-way communication, including attention to cultural issues, contribute to knowledge development; and a focus on competence and goal achievement, including multicultural activities, lead to skill development. In this manner, the data suggest that increased multicultural competence is a potential result from this model of cross-cultural supervision.

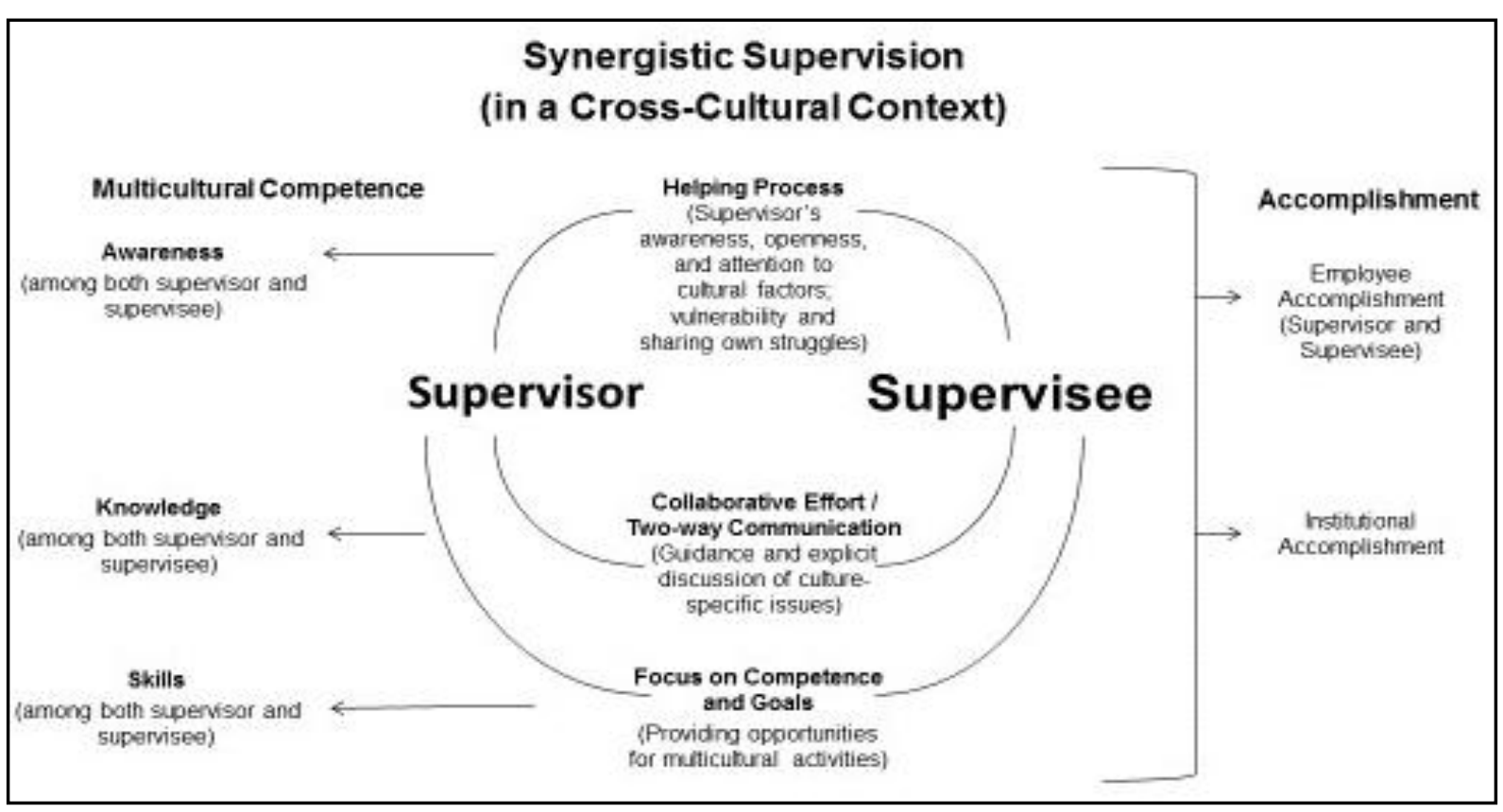

Figure 1. Cross cultural supervision model

In addition, Shupp and Arminio [39] asserted that a synergistic supervisory relationship "results in success for both the individuals involved as well as the organization". Consequently, though additional research is needed to support this model, we believe that its use should enhance the accomplishments of supervisors and supervisees as well as, to the extent that the model is prevalent across campus, institutional accomplishments. In this manner, we believe that our participants would have benefited from the model. Previous literature has established the importance of supervision in student affairs for the development and retention of young professionals. The findings of this study support the notion that the most effective supervision "happens deliberately through an open, dynamic, and vital relationship between supervisor and staff member"

Moreover, the findings emphasize the interrelationship of identity and supervision, demonstrating that culture is too important to be treated superficially by supervisors.

\section{References}

[1] Ancis, J. R., \& Marshall, S. (2010). Using a multicultural framework to assess supervisee's perceptions of culturally competent supervision. Journal of Counseling and Development, 88, 277-284.

[2] Arminio, J., \& Creamer, D. G. (2001). What supervisors say about quality supervision. College Student Affairs Journal, 21(1), 35-44.

[3] Arredondo, P. (1996). Successful diversity management initiatives. Thousand Oaks, CA: Sage.

[4] Barham, J. D., \& Winston, Jr., R. B. (2006). Supervision of new professionals in student affairs:

Assessing and addressing needs. College Student Affairs Journal, 26(1), 64-89.

[5] Brinson, J. (2004). Recognizing our cultural biases as counselor supervisors: A reflective learning approach. Guidance \& Counseling, 19(2), 81-91.

[6] Brown, M. T, \& Landrum-Brown, J. (1995). Counselor supervision: Cross-cultural perspectives. In J. G. Ponterotto, J. M. Casas, L. A. Suzuki, \& C. M. Alexander (Eds.), Handbook of multicultural counseling (pp. 263-286). Thousand Oaks, CA: Sage. 
[7] Chase, S. E. (2005). Narrative inquiry: Multiple lenses, approaches, voices. In N. K. Denzin \& Y. S. Lincoln (Eds.) Collecting and interpreting qualitative research (3rd ed.; pp. 651-680). Thousand Oaks, CA: Sage.

[8] Cilente, K., Henning, G., Skinner, J., Kennedy, D., \& Sloane, T. (2006). Report on the new professional needs study. Washington, DC: American College Personnel Association. Retrieved from http://myacpa.org/ research/ newprofessionals.php. (Access Date: 4 September 2016)

[9] Clandinin, D. J., \& Connelly, F. M. (2000). Narrative inquiry: Experience and story in qualitative research. San Francisco, CA: Jossey-Bass.

[10] Clandinin, D. J., \& Rosiek, J. (2007). Mapping a landscape of narrative inquiry: Borderland spaces and tensions. In D. J. Clandinin (Ed.), Handbook of narrative inquiry: Mapping a methodology (pp. 35-75). Thousand Oaks, CA: Sage.

[11] Constantine, M. G. (1997). Facilitating multicultural competency in counselor supervision: Operationalizing a practical framework. In D. B. Pope-Davis \& H. L. K. Coleman (Eds.), Multicultural counseling competencies: Assessment, education and training, and supervision (pp. 310-324). Thousand Oaks, CA: Sage.

[12] Cook, D. A. (1994). Racial identity in supervision. Counselor Education and Supervision, 34, 132-141.

Creswell, J. W. (2013). Qualitative inquiry and research design: Choosing among five tradition (3nd ed.). Thousand Oaks, CA: Sage.

[13] Daniels, J., D'Andrea, M., \& Kim, B. S. K. (1999). Assessing the barriers and changes of crosscultural supervision: A case study. Counselor Education and Supervision, 38, 191-204.

[14] Davis, T. J. (2013). Developing new professionals: Complex narratives of supervision in student affairs (Doctoral dissertation). Retrieved from https://getd.libs.uga.edu/pdfs/davis_tiffany_j_201305_ph d.pdf. (Access Date: 4 September 2016)

[15] Drewes, A. A. (2008). Culturally competent supervision of child and play therapists. In A.A. Drewes \& J.A. Mullen (Eds.), Supervision can be playful. Techniques for child and play therapy supervisors (pp. 77-90). Lanham, MD: Jason Aronson, Rowman \& Littlefield.

[16] Egbert, J., \& Sanden, S. (2014). Foundations of education research: Understanding theoretical components. New York: Routledge.

[17] Estrada, D., Wiggins Frame, M., \& Braun-Williams, C. (2004). Cross-cultural supervision: Guiding the conversation toward race and ethnicity. Journal of Multicultural Counseling and Development, 32, 307-319.

[18] Fukuyama, M. A. (1995). Critical incidents in multicultural counseling supervision: A phenomenological approach to supervision research. Counselor Education and Supervision, 34, 142-151.
[19] Gardner, R. M. D. (2002). Cross cultural perspectives in supervision. Western Journal of Black Studies, 26(2), 98-106.

[20] Gatmon, D., Jackson, D., Koshkarian, L., MartosPerry, N., Molina, A., Patel, N. \& Rodolfa, E. (2001), Exploring ethnic, gender, and sexual orientation variables in supervision: Do they really matter? Journal of Multicultural Counseling \& Development, 29, 102-113. doi: 10.1002/j.2161-1912.2001.tb00508.x

[21] Harned, P., \& Murphy, M. (1998). Creating a culture of development for the new professional. In. W. A. Bryan \& R. A. Schwartz (Eds.), Strategies for staff development: Personal and professional education for the 21st century, New directions for student services, No. 84 (pp. 45-53). San Francisco, CA: Jossey-Bass.

[22] Hirt, J. B. (2006). Where you work matters: Student affairs administration at different types of institutions. Lanham, MD: University Press of America.

[23] Jackson, J. F. L., \& O'Callaghan, E. M. (2009). Ethnic and racial administrative diversity: Understanding work life realities and experiences in higher education. ASHE Higher Education Report, vol. 35. San Francisco, CA: Jossey-Bass.

[24] Jones, S. R., Torres, V. \& Arminio, J. (2014). Negotiating the complexities of qualitative research in higher education (2nd ed.). New York, NY: Routledge.

[25] Leong, F. T. L., \& Wagner, N. S. (1994). Crosscultural counseling supervision: What do we know? What do we need to know? Counselor Education and Supervision, 34(2), 117-131.

[26] Manathunga, C. (2011). Moments of transculturation and assimilation: Post-colonial explorations of supervision and culture. Innovations in Education and Teaching International, 48(4), 367-376.

[27] Marsh, S. R. (2001). Using adult development theory to inform staff supervision in student affairs. College Student Affairs Journal, 21(1), 45-56.

[28] Morris, W. \& Morris, M. (1988). Harper dictionary of contemporary usage (2nd ed.). New York, NY: HarperCollins.

[29] Nelson, M. L., Gizara, S., Hope, A. C., Phelps, R., Steward, R., \& Weitzman, L. M. (2006). A feminist multicultural perspective on supervision. Journal of Multicultural Counseling and Development, 34, 105-115.

[30] Page, M. L. (2003). Race, culture, and the supervisory relationship: A Review of the literature and a call to action. Journal of Curriculum and Supervision, 18(2), 161-174.

[31] Patton, M. Q. (2002). Qualitative evaluation and research methods (3rd ed.). Newbury Park, CA: Sage.

[32] Pope, R. L., Reynolds, A. L., \& Mueller, J. A. (2004). Multicultural competence in student affairs.San Francisco: Jossey-Bass. 
[33] Pope, R. L., Reynolds, A. L., \& Mueller, J. A. (2014). Creating multicultural change on campus. San Francisco, CA: Jossey-Bass.

[34] Renn, K. A. \& Hodges, J. P. (2007). The first year on the job: Experiences of new professionals in student affairs. NASPA Journal, 44(2), 367-391.

[35] Saunders, S. A., Cooper, D. L., Winston, R. B., Jr., \& Chernow, E. (2000). Supervising staff in student affairs: Exploration of the synergistic approach. Journal of College Student Development, 41, 181-192.

[36] Scarcia-King, T. J. (2011). Effective strategies for virtual supervision. In L. D. Roper (Ed.). Supporting and supervising mid-level professionals. New directions for student services. (no. 136, pp. 55-67). San Francisco, CA: Wiley. doi: 10.1002/ss.414.

[37] Scheuermann, T. (2011). Dynamics of supervision. In L. D. Roper (Ed.). New directions for student services: Supporting and supervising mid-level professionals (no. 136, pp. 5-16). San Francisco, CA: Jossey-Bass. doi: $10.1002 /$ ss.409.

[38] Shupp, M. (2007). Synergistic supervision: An analysis of one key to retaining entry-level student affairs professionals. Dissertation Abstracts International, 69A(1). (Publication No. AAT 3298302).

[39] Shupp, M. \& Arminio, J. L. (2012). Synergistic supervision: A confirmed key to retaining entry-

level student affairs professionals. Journal of Student Affairs Research and Practice, 49(2), 157-174. doi:10.1515/jsarp-2012-6295.

[40] Stock-Ward, S. R., \& Javorek, M. E. (2003). Applying theory to practice: Supervision in student affairs. NASPA Journal, 40(3), 77-92.

[41] Toporek, R. L., Ortega-Villalobos, L., \& PopeDavis, D. B. (2004). Critical incidents in multicultural supervision: Exploring supervisees' and supervisors' experiences. Journal of Multicultural Counseling and Development, 32, 66-83.

[42] Tull, A. (2006). Synergistic supervision, job satisfaction, and intention to turnover of new professionals in student affairs. Journal of College Student Development, 47(4), 465-480. doi: 10.1353/jcsd.2006.0053.

[43] White, J. \& Nonnamaker, J. (2011). Supervising graduate assistants. In L. D. Roper (Ed.). Supporting and supervising mid-level professionals. New directions for student services. (no. 136, pp. 43-54). San Francisco, CA: Wiley. doi: 10.1002/ss.413.

[44] Winston, R. B., Jr., \& Creamer D. G. (1997). Improving staffing practices in student affairs. San Francisco, CA: Jossey-Bass.

[45] Winston, R. B., Jr., \& Creamer, D. G. (1998). Staff supervision and professional development: An integrated approach. In W. A. Bryan \& R. A. Schwartz (Eds.), Strategies for staff development: Personal and professional education in the $21 \mathrm{st}$ century, New directions for student services, No. 84 (pp. 29-42). San Francisco, CA: Jossey-Bass.

[46] Wong, L. C. J., Wong, P. T. P., \& Ishiyama, F. I. (2012). What helps and what hinders in cross-cultural clinical supervision: A critical incident study. The Counseling Psychologist, 41(1), 66-85. doi: 10.1177/0011000012442652. 